\title{
Measurement of psycho-emotional constructs and self-management in health of patients with Rheumatics diseases
}

\author{
Ana Dalla Santana Lima ${ }^{1}$, Clesnan Mendes-Rodrigues ${ }^{1}$, Laysa Oliveira Santos Dias ${ }^{1}$, Eliana Borges Silva Pereira ${ }^{2}$, \\ Omar Pereira de Almeida-Neto ${ }^{1}$, Igor Oliveira Felice ${ }^{3}$, Cristiane Martins Cunha ${ }^{* 1}$ \\ ${ }^{1}$ Nursing, Medicine Faculty, Federal University of Uberlândia, Uberlândia, Brazil \\ ${ }^{2}$ Clinical Hospital of Uberlândia, Federal University of Uberlândia, Uberlândia, Brazil \\ ${ }^{3}$ Faculty of Mechanical Engineering, Federal University of Uberlândia, Uberlândia, Brazil
}

Received: May 14, 2018

DOI: $10.5430 /$ jnep.v8n11p1
Accepted: May 23, 2018

Online Published: June 4, 2018

\begin{abstract}
Objective: This study aimed to measure the scores of psychoemotional and self-management constructs in patients with rheumatic diseases (RD), to compare these scores according to the RD type and to verify the influence of these measures on self-management in health.

Methods: Cross-sectional study, carried out in an ambulatory of a public hospital of Brazil. Adult patients, with diagnosis of RD, responded to self-esteem, anxiety and depression, health and activation scales. Spearman's correlation tests, independence tests, mean or median tests, multiple linear regressions evaluated the variables of interest at a significance level of .05.

Results: Eighty-six patients (mean age $=45.23, \mathrm{SD}=14.30)$ were evaluated. High activation $(\mathrm{mean}=65.83, \mathrm{SD}=14.20)$ and self-esteem scores $($ mean $=30.67, \mathrm{SD}=5.65)$ were observed, while moderate anxiety scores $($ mean $=8.21, \mathrm{SD}=4.37)$ and low scores for depression (mean $=6.37, \mathrm{SD}=3.98$ ). Significant correlations were observed, from low to moderate magnitude, among other measures with activation $(p<.05)$. There were weak correlations between activation and formal study time, self-esteem with age and family income, depression and number of comorbidities diagnosed or self-reported $(p<.05)$. The RD type no affects any of the constructs evaluated.

Conclusions: It was concluded that patients with rheumatic diseases presented high self-esteem, moderate anxiety levels and low levels of depression and a high level of activation. Lower number of diagnosed comorbities, higher formal study time was related to better self-management in health.
\end{abstract}

Key Words: Self-eestem, Depression, Anxiety, Self concept, Lupus erythematosus systemic, Arthritis rheumatoid

\section{INTRODUCTION}

Rheumatic diseases are chronic diseases that generate negative implications in the physical, psychological and social spheres in their patients. ${ }^{[1]}$ Systemic lupus erythematosus (SLE) and rheumatoid arthritis (RA) are examples of rheumatic diseases (RD), ${ }^{[2,3]}$ characterized by persistent inflammatory reactions, especially articular ones, accompanied by pain and fatigue and alteration of the body image. ${ }^{[3]}$

Rheumatoid arthritis is a systemic and progressive inflammatory disease that affects individuals of productive age leading

\footnotetext{
*Correspondence: Cristiane Martins Cunha; Email: cristiane.cunha@ufu.br; Address: Enfermagem, Faculdade de Medicina, Universidade Federal de Uberlândia, Av. Pará 1720, Uberlândia, MG, Brazil. 
to the loss of labor capacity, an important limitation in functional capacity and quality of life, ${ }^{[4-6]}$ due to its clinical manifestations, which may be both articular and extra-articular. ${ }^{[7]}$ In addition to irreversible deformity and functional limitation, their patients may present lower survival rates. ${ }^{[8,9]}$

The SLE is an autoimmune and multisystemic disease caused by both genetic and environmental factors. ${ }^{[10-12]}$ It consists of chronic inflammation of various organs of the individual, especially joints, skin and kidneys, compromising their function simultaneously or successively. ${ }^{[13]}$ Its symptoms are varied and occur according to the affected area. ${ }^{[14,15]}$

The rheumatic diseases approach includes patient and family education, drug therapy, physiotherapy, psychosocial support, occupational therapy and even surgical approaches. ${ }^{[9]}$ Health education should be implemented as soon as possible $e^{[16,17]}$ with the objective of self-managing their health to have better health outcomes.

However, living with pain, physical limitations, high financial and social costs and changes in physical appearance, generate great uncertainty and intense emotional impact to the individual. ${ }^{[3]}$ Thus, it is necessary that health professionals carry out individualized approaches and draw strategies that help patients to face their condition, adapting to the changes demanded in life habits. It is important that patients take control of preventive measures as well as procedures to manage the signs and symptoms related to the disease, ensuring that self-care and self-management of health are satisfactory, in order to minimize the progression of the disease. ${ }^{[11]}$

The psycho-emotional and self-esteem aspects of the individual with rheumatic diseases can interfere in changes in the life habits required by their condition. Thus, it is vitally important that health professionals attend to the aspects of self-management in health, in order to achieve better results. In this context, the present study aimed to measure self-esteem, anxiety and depression and the level of health self-management (activation) in a group of patients with rheumatic diseases, crossing the influence of different social, demographic and clinical characteristics with these measures.

\section{METHOD}

\subsection{Type of study, location and ethical considerations}

Cross-sectional, analytical and descriptive study with a quantitative approach. This study included individuals with rheumatic diseases who were in treatment at the Rheumatology Outpatient Clinic of the Clinical Hospital of Uberlândia ("Hospital de Clínicas de Uberlândia"), a university hospital in Uberlândia, Minas Gerais state, Brazil. This research was approved by the Research Ethics Committee, CAAE $n^{\circ}$
22127213.2.0000.5393, and the data collection period was from July to September 2014.

\subsection{Sample, inclusion and exclusion criteria}

The sample was non-probabilistic, for convenience, of the consecutive type. In order to compose the sample, the following inclusion criteria were adopted: individuals with a diagnosis of rheumatic diseases for at least six months, aged between 18 and 80 years, with cognitive preservation ${ }^{[18]}$ and who underwent regular clinical follow-up at the Rheumatology Outpatient Clinic. The exclusion criterion was all individuals who had previous hospitalization within a period of up to one month.

\subsection{Data collection procedures}

Participants were approached and invited to participate in the study before the medical appointment and, after that, the clarifications were carried out. After all the clarifications and the patients acceptance, it was asked to sign the "Free Consent and Clarified Term". Firstly, the cognitive state was verified through an instrument for assessing the individual's discriminatory capacity and mental and psychic orientation in time and space, according to Pfeiffer's ${ }^{[18]}$ proposal. In order to be considered apt, the patient was required to provide correct answers for three of the four questions. After the cognitive status was screened, the evaluative questionnaires were applied in a private setting and, later, the information of the clinical records was collected from the patients' records.

In the characterizing questionnaire the socio-demographic data evaluated: gender, age (in completed years), marital status, education level (in grade and in years of formal study), number of comorbidities self-reported, number of comorbidities diagnosed and monthly gross family income (in Reais, the Brazilian currency wich from July to September 2014 for 1 US\$ oscillate from 2.203 to 2.455 Reais, mean $=2.274$ ). The information on clinical data evaluated was obtained from the medical diagnosis as the time of diagnosis and the number of comorbidities. The comorbidities evaluated were systemic arterial hypertension, diabetes mellitus, thyroid diseases, anxiety, depression, hematologic diseases, dyslipidemia, obesity, heart disease, nephropathy, rheumatism, cancer, systemic lupus erythematosus, gastric and enterological diseases, liver disease and neurological diseases.

In addition, some Brazilian validated versions of the following instruments were applied: The Rosenberg Self-Esteem Scale wich score oscillate from 10 to 40 points (RSES), ${ }^{[19]}$ for self-esteem evaluation. The higher the score, the higher the level of self-esteem of the person.

The "Hospital Anxiety and Depression Scale" (HADS) composed by two subscales (anxiety or depression subscale), and 
the scores oscillate from 0 to 21 points in each subscale, ${ }^{[20]}$ for assessing the presence of anxiety and depression symptoms. The higher points are indicating greater presence of symptoms in each subscale.

The Patient Activation Measure 13 (PAM13) to assess health self-management (or activation) of the patients wich scores oscillate from 13 to 52 points in raw score. ${ }^{[21,22]}$ The raw score and then converted to an activation score ranging from 0 to 100 points, and higher scores refer to the highest level of activation. ${ }^{[21,22]}$

For the evaluation of self reported health status, the version of the Analogic Visual Scale (AVS), that composes the Euroqol instrumernt (EQ-5D) called EQ-AVS ${ }^{[23,24]}$ was used. The scores oscillate from 0 to 100 points. The higher score values are indicating better self-perception of health.

\subsection{Statistical treatment}

The data were stored in spreadsheets (Microsoft Office Excell for Windows (R) and processed by the IBM Statistical Package for Social Sciences (SPSS) software version 21.0, running in a Windows $\mathrm{R}$ environment. We adopted a significance level of 0.05. Simple frequency descriptive analyzes were performed for categorical variables, and measures of central tendency (mean and median) and variability (standard deviation) for continuous variables.

The descriptive statistics of absolute and relative frequency, central tendency and variability of the instrument scores were used to measure and analyze the scores of the self-esteem, anxiety and depression, activation and health status. For data interpretation, the recommendations of the authors who validated the instruments for the Brazilian population were applied. All instruments scores when stratified by rheumatic diseases type present data with Gaussian distribution, adopting the Shapiro Wilk test and 0.01 of significance, and when evaluated independently also show Gaussian distribution, except the AVS, evaluated by Kolmogorv Smirnov Liliefors test.

Spearman's correlation was used between the variables of interest to analyze the correlation between social, demographic and clinical variables with measures of self-esteem, anxiety, depression, activation and health status. Student $t$ test were applied among the variables of interest, to verify if there was a difference between the measures of self-esteem, anxiety, depression, health status and activation between the two types of RD. The magnitude of the correlations adopted was: correlation values below 0.30 have low clinical applicability (although they have statistical significance); values between 0.30 and 0.50 indicate a moderate correlation and values greater than 0.50 represent a strong clinical correlation ${ }^{[25]}$

Published by Sciedu Press and their significance tested with Student $t$ test.

Mann-Whitney test was used between the continuous variables of interest to analyze the differences in profile from the two types of rheumatic disease type patients. Qui-square test was used between the qualitative variables from the same profile.

As some characteristics from the profile of the patients were associated with the instruments scores and in all cases we have multifactorial traits that could influence each construct or dimension, we applied multiple liner regression by ordinary least square method to verify the impact of the profile in the instrument score. We adopted each instrument score as dependent variable and as predictor variables the Gender (0: female; 1: male), age (in years), formal study time (in years), marital status (0: other, 1: married or stable union), gross family income (in Reais), Rheumatic Disease Type (0: rheumatoid arthritis; 1: systemic lupus erythematosus), number of comorbidities diagnosed, number of comorbidities self-reported and the diagnostic time (in years). We adopted the backward method for variable selection with criteria the probability of 0.05 in both cases (inclusion and exclusion). We not included each comorbidity individually in the model based in small sample size and low prevalence from some comorbidities.

\section{RESUlts}

In this study, 86 patients with rheumatic diseases were studied, and $77(89.5 \%)$ were women. The mean age of participants was 45.23 years $(\mathrm{SD}=14.30)$, with a predominant age range of 30 to 59 years $(56 ; 65.1 \%)$ followed by $\geq 60$ years $(16,18.6 \%)$ and 18 to 29 years $(14,16.3 \%)$. Less than half of the participants were married or living in stable union (33; $38.4 \%)$. In $58(67.4 \%)$ of the participants, they reported occupational activity. The predominant education level was High School $(32,37.2 \%)$, followed by Basic $(22,25.6 \%)$, Elementary $(18,21.0 \%)$, College $(12,14.0 \%)$ and Post-Graduation $(2,2.2 \%)$. The mean years of formal education was 8.73 years $(\mathrm{SD}=4.08)$ and the average family income was 1838 Reais ( $\mathrm{SD}=1300.97)$. Most of the participants evaluated had RA $(51 ; 59.3 \%)$. The main diagnosis time was 12.29 years $(\mathrm{SD}=8.55)$. It is observed the disparity between the numbers of comorbidities diagnosed (mean 2.63) in relation to the number of self-reported comorbidities (mean 11.98), the latter being much higher (see Table 1).

It was verified that the evaluated rheumatic disease patients had high activation scores $($ mean $=65.83$ ) and self-esteem (mean $=30.67)$. Regarding the presence of symptoms of anxiety and depression, it is observed that the anxiety scores revealed a moderate presence of anxiety symptoms (mean 
$=8.21$ ), but the presence of depressive symptoms was not health status of this population was considered high (AVS verified in the evaluated group $($ mean $=6.37)$. The perceived mean $=64.83)($ see Table 2$)$.

Table 1. Social, demographic and clinical characteristics of patients with rheumatic diseases

\begin{tabular}{|c|c|}
\hline Characteristics & Number (\%) \\
\hline \multicolumn{2}{|l|}{ Gender } \\
\hline Female & 77 (89.5) \\
\hline Male & $9(10.5)$ \\
\hline \multicolumn{2}{|l|}{ Marital Status } \\
\hline Married or Stable Union & $33(38.4)$ \\
\hline Others & $53(61.6)$ \\
\hline \multicolumn{2}{|l|}{ Employment } \\
\hline Inactive & $28(32.6)$ \\
\hline Active & $58(67.4)$ \\
\hline \multicolumn{2}{|l|}{ Rheumatic Disease Type } \\
\hline Rheumatoid arthritis & $51(59.3)$ \\
\hline \multirow[t]{2}{*}{ Systemic lupus erythematosus } & 35 (40.7) \\
\hline & Mean \pm Standard Deviation [variation] (median) \\
\hline Age (in years) & $45.23 \pm 14.30$ [19-78] (47.50) \\
\hline Formal Study Time (in years) & $8.73 \pm 4.08[1-18](10.00)$ \\
\hline Gross family income (in Reais) & $1838 \pm 1,300.97[500-8,000](1,500)$ \\
\hline Number of comorbidities diagnosed & $2.63 \pm 1.95[0-8](2.00)$ \\
\hline Number of comorbidities self-reported & $11.98 \pm 1.88[7-14](10.00)$ \\
\hline Diagnostic time (in years) & $12.29 \pm 8.55[5-33](12.00)$ \\
\hline
\end{tabular}

Table 2. Mean, median scores, standard deviations (SD) and variations obtained from instrument measures of self-esteem, anxiety and depression, activation and health status of patients with rheumatic diseases $(\mathrm{n}=86$ patients)

\begin{tabular}{llll}
\hline Instrument & Mean \pm SD & Median & Variation \\
\hline Patient Activation Measure 13 & $65.83 \pm 14.20$ & 66 & $40.1-100$ \\
Rosenberg Self-Esteem Scale & $30.67 \pm 5.65$ & 31 & $17-40$ \\
Hospital Anxiety Depression Scale - Anxiety subscale & $8.21 \pm 4.37$ & 8 & $1-21$ \\
Hospital Anxiety Depression Scale - Depression subscale & $6.37 \pm 3.98$ & 6 & $0-16$ \\
Analogic Visual Scale & $64.83 \pm 20.53$ & 65 & $0-100$ \\
\hline
\end{tabular}

The rheumatic diseases types profile not differ as the gen$\operatorname{der}\left(\chi^{2}=2.40, p=.121\right)$, and marital status $\left(\chi^{2}=0.001\right.$, $p=.975)$ but differ as the education level $\left(\chi^{2}=16.13, p=\right.$ $.024)$. For continuous variables the RD types differ as the age $(\mathrm{RA}$ median $=51$, SLE median $=34 ; \mathrm{Z}=4.17, p<.001$ ), formal study time (RA median $=8$, SLE median $=11 ; \mathrm{Z}=$ $3.60, p<.001)$; and were equals for gross family income $(\mathrm{Z}=0.71, p=.479)$, number of comorbidities diagnosed $(\mathrm{Z}=1.67, p=.095)$, number of comorbidities self-reported $(\mathrm{Z}=0.73, p=.465)$ and diagnostic time $(\mathrm{Z}=1.58, p=$ .112). In the comparison between the self-esteem, anxiety and depression, activation and health status mean scores, all the measurements no showed statistical differences in the scores of patients with rheumatoid arthritis and systemic lupus erythematosus ( $p>.05$, see Table 3$)$. This last result may have been generated by statistical differences in some of the variables in the profile of these two RD types.

Regarding the evaluation of the relationship between the measures of self-esteem, health status, anxiety and depression and activation with some socio-demographic and clinical variables, a weak and significant correlation was observed only between activation (PAM13) and formal study time in years $\left(r_{s}=0.327, p<.05\right)$, measure of self-esteem (RSES) and gross family income $\left(r_{s}=0.227, p<.05\right)$ and age (rs $=0.246, p<.05)$, and depression measure (HADS-D) with the number of comorbidities self-reported $\left(r_{s}=-0.224, p<\right.$ 
$.05)$ and number of comorbidities diagnosed $\left(r_{s}=0.229, p\right.$ itively the PAM13 (Bi $\left.=0.86, p=.022\right)$ and the RSES (Bi $<.05)$. In relation to the other variables and instruments of $=0.47, p=.004)$ and negatively the HADS-D (Bi $=-0.29$, measurement, there was no other significant correlation. All instruments scores were correlated with each other, except the PAM13 and AVS, and the HADS-D and AVS (see Table 4).

The behavior of the instruments was also evaluated in a multifactorial view according to some predictive profile traits. We found that the number of formal study time affects pos-

$p=.003)$. The employment status, inactive, affects negatively the HADS-A ( $\mathrm{Bi}=-1.96, p=.047)$. The number of comorbidities diagnoses affects positively the HADS-A (Bi $=0.49, p=.038)$ and the HADS-D $(\mathrm{Bi}=0.44, p=.029)$. The gender, male, affected negatively the HADS-D; that also was affected negatively by and marital status, stable union. The unique instrument that was not affected by profile was the AVS (see Table 5).

Table 3. Comparison between mean scores obtained from instrument measures of self-esteem, anxiety and depression, activation and health status of patients with rheumatic diseases stratified by type as rheumatoid arthritis $(\mathrm{n}=51)$ and systemic lupus erythematosus $(\mathrm{n}=35)$

\begin{tabular}{llll}
\hline \multirow{2}{*}{ Instrument } & \multicolumn{2}{l}{ Rheumatoid arthritis } & \multicolumn{2}{l}{ Systemic lupus erythematosus } \\
\cline { 2 - 3 } $\boldsymbol{p}^{*}$ & \multicolumn{2}{l}{ Mean \pm Standard Deviation } \\
\hline Patient Activation Measure & $64.20 \pm 14.42$ & $68.19 \pm 13.73$ & .201 \\
Rosenberg Self-Esteem Scale & $31.06 \pm 5.30$ & $30.11 \pm 6.15$ & .450 \\
Hospital Anxiety Depression Scale-Anxiety subscale & $8.67 \pm 4.69$ & $7.54 \pm 3.84$ & .244 \\
Hospital Anxiety Depression Scale-Depression subscale & $6.51 \pm 4.16$ & $6.17 \pm 3.74$ & .701 \\
Analogic Visual Scale & $64.52 \pm 22.35$ & $65.28 \pm 17.86$ & .866 \\
\hline
\end{tabular}

*p: probability based on Student's $t$ test with homogeneous variance

Table 4. Spearman correlation applied to scores obtained from instrument measures of self-esteem, anxiety and depression, activation and health status of patients with rheumatic diseases and quantitative traits from profile $(\mathrm{n}=86$ patients)

\begin{tabular}{llllll}
\hline Trait & PAM13 & RSES & HADS-A & HADS-D & AVS \\
\hline Age (in years) & $-.190 \mathrm{~ns}$ & $.246^{*}$ & $-.020 \mathrm{~ns}$ & $-.028 \mathrm{~ns}$ & $.069 \mathrm{~ns}$ \\
Gross family income (in Reais) & $.002 \mathrm{~ns}$ & $.227^{*}$ & $-.092 \mathrm{~ns}$ & $-.192 \mathrm{~ns}$ & $-.048 \mathrm{~ns}$ \\
Formal study time (in years) & $.327^{* *}$ & $.106 \mathrm{~ns}$ & $-.194 \mathrm{~ns}$ & $-.210 \mathrm{~ns}$ & $-.085 \mathrm{~ns}$ \\
Number of comorbidities self-reported & $.118 \mathrm{~ns}$ & $.122 \mathrm{~ns}$ & $-.137 \mathrm{~ns}$ & $-.224^{*}$ & $-.034 \mathrm{~ns}$ \\
Number of comorbidities diagnosed & $-.153 \mathrm{~ns}$ & $-.122 \mathrm{~ns}$ & $.182 \mathrm{~ns}$ & $.229^{*}$ & $.035 \mathrm{~ns}$ \\
Diagnostic time (in years) & $-.092 \mathrm{~ns}$ & $-.081 \mathrm{~ns}$ & $.141 \mathrm{~ns}$ & $.081 \mathrm{~ns}$ & $.057 \mathrm{~ns}$ \\
PAM13 & & $.399 * *$ & $-.242^{*}$ & $-.315^{* *}$ & $.161 \mathrm{~ns}$ \\
RSES & & & $-.645^{* *}$ & $-.668^{* *}$ & $.297^{* *}$ \\
HADS-A & & & & $.600^{* *}$ & $-.303^{* *}$ \\
HADS-D & & & & & $-.152 \mathrm{~ns}$
\end{tabular}

${ }^{*} p<.05,{ }^{* *} p<.01$, ns: $p>.05, p$ : probability based on Student's $t$ test, PAM13: Patient Activation Measure 13, RSES: Rosenberg Self-Esteem Scale, HADS-A: Hospital Anxiety Depression Scale - Anxiety subscale, HADS-D: Hospital Anxiety Depression Scale - Depression subscale, AVS: Analogic Visual Scale.

\section{Discussion}

The present study measured the subjective constructs of self-esteem, anxiety and depression, health status and selfmanagement in health (activation) of patients with rheumatic diseases and correlated these scores with different social, demographic and clinical characteristics.

It was verified the predominance of women in this sample and similar results to other studies. ${ }^{[2,3,26-28]}$ According to Mota et al., ${ }^{[9]}$ RA preferentially affects women in a ratio of 3:1. In the same way, authors affirm that SLE also affects Published by Sciedu Press women, but young ones and in a ratio of 10:1..$^{[29,30]}$ The female gender also was associated with an increase in de HADS-D score, but the gender not differs among the RD types as in these studies.

The mean age of the participants was around 45 years, with a predominant age group of 30 to 59 years old, similar to other studies. ${ }^{[27,28,31-33]}$ According to Mota et al. ${ }^{[9]} \mathrm{RA}$ affects all age groups, but it has a higher prevalence from 40 to 60 years. However, SLE prevails during the fertile age. ${ }^{[30]}$ Patients with more age also show better RSES, self-esteem increase with the age in the RD patients. 
Table 5. Multiple linear regression applied to scores obtained from instrument measures of self-esteem, anxiety and depression, activation and health status of patients with rheumatic diseases $(\mathrm{n}=86)$

\begin{tabular}{|c|c|c|c|c|c|c|}
\hline Instrument & Predictor & Bi & $S E$ & $t$ & $p$ & $r^{2}$ \\
\hline \multirow{2}{*}{ PAM13 } & Constant & 58.33 & 3.54 & 16.47 & $<.001$ & \multirow{2}{*}{.050} \\
\hline & Formal study time (in years) & 0.86 & 0.37 & 2.34 & .022 & \\
\hline \multirow{3}{*}{ HADS-A } & Constant & 8.23 & 1.03 & 8.00 & $<.001$ & \multirow{3}{*}{.076} \\
\hline & Employment (0: active, 1: inactive) & -1.96 & 0.97 & -2.02 & .047 & \\
\hline & Number of comorbidities diagnosed & 0.49 & 0.24 & 2.10 & .038 & \\
\hline \multirow{5}{*}{ HADS-D } & Constant & 9.64 & 1.31 & 7.37 & $<.001$ & \multirow{5}{*}{.243} \\
\hline & Gender (0: female, 1 : male) & -3.67 & 1.24 & -2.96 & .004 & \\
\hline & Marital status (1: stable union; 0: others) & -2.44 & 0.79 & -3.10 & .003 & \\
\hline & Formal study time (in years) & -0.29 & 0.10 & -3.05 & .003 & \\
\hline & Number of comorbidities diagnosed & 0.44 & 0.20 & 2.23 & .029 & \\
\hline \multirow{4}{*}{ RSES } & Constant & 19.30 & 3.06 & 6.32 & $<.001$ & \multirow{4}{*}{.175} \\
\hline & Age (in years) & 0.21 & 0.05 & 4.29 & $<.001$ & \\
\hline & Formal study time (in years) & 0.47 & 0.16 & 2.97 & .004 & \\
\hline & Number of comorbidities diagnosed & -0.76 & 0.30 & -2.52 & .014 & \\
\hline AVS & Constant & 64.83 & 2.21 & 29.28 & $<.001$ & .000 \\
\hline
\end{tabular}

Note. Bi: i-th parameter estimative, SE: standard error from the Bi, $t$ : statistic $t$ of Student's $t$ test, $p$ : probability, $r^{2}$ : adjusted $r$ squared, PAM13: Patient Activation Measure 13, RSES: Rosenberg Self-Esteem Scale, HADS-A: Hospital Anxiety Depression Scale - Anxiety subscale, HADS-D: Hospital Anxiety Depression Scale - Depression subscale, AVS: Analogic Visual Scale.

On the marital status, less than half of the participants (38.4\%) live together with a partner, discordant with other studies, which the majority of the participants affirmed to be engaged. ${ }^{[1,3,28,32]}$ The engagement has a positive impact for patients with RD, once decrease the scores from the HADS$D$. The presence from a partner decreases the symptoms of depression in these patients.

Regarding to occupational activity, more than half of the participants reported having work activity, corroborating with the Ayache study, ${ }^{[32]}$ which $56 \%$ of the sample declared to work. However, these results are discordant with other studies, in which less than half of the participants declared themselves employed. ${ }^{[1,11,28]}$ SLE is associated with chronic pain, extreme fatigue, sleep disturbances, cognitive dysfunction, anxiety and depression, which negatively affect work and social roles. ${ }^{[34]}$ Similarly, RA affects patients of productive age and can determine an important limitation in functional capacity, social relationships and loss of work capacity, resulting from the coexistence with pain and potential irreversible joint damage. ${ }^{[35]}$ These symptoms associated with a lack of employment increase the anxiety of patients, verified by the increase of HADS-A score in patients without employment. The employment has a positive impact in decrease the anxiety and could explained in this specifc group by the high scores of activation, self-eestem, perceived health status, and low scores of depression. The absence of the symptoms of depression or a good perceived health status corroborated that the patient has a job.

The average family income of the participants was about 2.73 minimum wages, as verified in other studies. ${ }^{[11,32]}$ The treatment of the effects of these two diseases is of great economical costs for the affected individual and for the society. ${ }^{[36,37]}$ Thus, a family income of around two to three minimum wages is considered low and limited to fulfill all the required therapeutic needs for these patients. Curiously, the family income was not associated positively or negatively with any score instrument evaluated here in the multifactorial approach.

The average formal educational time of the participants was around 9 years, slightly more high than another study, which prevailed a time of 4 to 7 years of study. ${ }^{[6]}$ According to Saintantonius; Yazigi; Sato et al., ${ }^{[26]}$ education is usually greatly impaired, both due to the need of absences as a consequence of the treatment, as well as to the evolution of the disease itself, which interferes with performance in general. The limitations imposed, either related to the care needed to make the disease inactive, it means by the own activity that leads to hospitalizations and, often, sequels, end up restricting social interaction and, with it, the possibility of exchange and stimulation that the environment offers. RA hinders access to formal education, but at the same time patients with more formal education time show better activation and 
self-eestem.

RA was the most prevalent disease in the group of patients studied in this study, which corroborates with other studies. ${ }^{[2,38,39]}$ Regarding the mean time of diagnosis of the disease, the patients presented a period around 12 years. In Hale's study; Radvanski; Hassett, ${ }^{[12]}$ this time ranged from 3 to 20 years, in another study, the time of diagnosis varied widely, ranging from 10 months to 36 years. ${ }^{[39]}$

Ardvidsson $^{[40]}$ points out that people with rheumatic diseases use various self-care behaviors to mitigate the disease, maintain independence and avoid loss of valuable life activities. ${ }^{[40]}$ These self-care behaviors are, for example, accepting illness, seeking positive attitudes, exercising regularly, using alternative treatment methods, and using distractions in activities that stimulate and maintain independence. ${ }^{[41]}$

In this context, high self-management on health (activation) scores were found in this study associated with more formal study time and with age. This result indicates that these patients have comprehensive knowledge about their health condition, safety in their actions, and the ability to act, make decisions and seek positive changes in health and lifestyle. Therefore, it is considered that the participants of this study are able to maintain their health condition and deal with the dismemberments coming from the disease.

The literature has demonstrated the benefits of effective selfmanagement of health, such as: individuals with chronic illnesses feel better and participate more in everyday activities, ${ }^{[42]}$ control physical and psychosocial symptoms, refer to a better state of health, reduction of pain and disability and seek to learn more about their disease and to develop new skills. ${ }^{[43]}$

The individuals who seek to acquire more knowledge about their disease, present greater adherence to the treatment and better quality of life and communication with health professionals. ${ }^{[44]}$ Thus, self-management reduces the use of health services and improves the social, psychological, functional, and clinical outcomes associated with chronic disease. ${ }^{[43]}$

Regarding self-esteem, a high self-esteem index was found in the group evaluated. However, patients with RA had the same self-esteem than patients with SLE. It is important to point out that high self-esteem promotes self-acceptance, self-respect and self-confidence, as well as feeling satisfaction for its ownself and own's actions. ${ }^{[45]}$ Authors affirm that high self-esteem is related to a lifestyle with responsible behaviors of self-care. ${ }^{[46]}$ And, from this point of view, and corroborating with this study, high self-esteem reflects in high levels of self-management in health.
However, other studies on rheumatic diseases have found low levels of self-esteem. ${ }^{[26,38,47]}$ According to Cornwell; Schmitt, ${ }^{[38]}$ the body image disorder among patients with RA is focused on body parts and features associated with physical ability. ${ }^{[38]}$ In individuals with SLE, the focus is more general about body image. According to Sato, ${ }^{[48]}$ physical changes and the evolution of SLE lead to insecurity, low self-esteem and depression. ${ }^{[48]}$ The absence of differences in constructs evaluated need additional studies with large samples to investigate better the associations with the profile and the RD type.

Some authors point out that living with a chronic and unpredictable illness generates adaptive emotional problems such as emotional stress, irritability, fatigue, emotional instability, insomnia, altered concentration and memory, problems with appetite, low self-esteem, insecurity, body image disturbances, suicidal ideation, decreased interest in the surrounding and limitations in social activities due to the needs that the condition imposes. ${ }^{[26,49]}$

As can be observed, individuals with rheumatic diseases present a series of multifactorial impacts in their life, being the emotional disorders one of the most frequent. In this study, the moderate presence of anxiety symptoms was verified, but no depressive symptoms were observed in the evaluated group. This can be attributed in some cases to the constant pain and physical limitations present in these individuals. ${ }^{[3]}$

On the other hand, SLE generates physical and psychoemotional impacts ${ }^{[50]}$ that lead to the interruption of plans, distancing from family and work and, consequently, mobilizes feelings such as anxiety, sadness, fear and anguish. ${ }^{[51]}$ The study by Skare et al. (2001) states that SLE patients suffer more from anxiety than the normal population, and such a finding is more frequent in those with an older age and a worse perception of their own health, associations not found here. Researchers state that depression and anxiety are the most frequent complaints in patients diagnosed with SLE, who seek psychological assistance, ${ }^{[26]}$ due to a serious impact on psychosocial well being. ${ }^{[12]}$

According to Campos et al., ${ }^{[27]}$ depression is closely related to the health status perceived, and the more depressive symptoms noticed, the worse is the perception of health status. In this study, as the symptoms of depression were low, equivalent of the general population, it is possible to infer that these emotional aspects did little interference in the state of health of the participants, reinforced by absence of correlation among HADS-D and AVS. Cornwell; Schmitt, ${ }^{[38]}$ affirm that better health status is associated with higher self-esteem and perception of body image. Patients with higher RSES 
(higher Self-Esteem) and higher activation show lower scores from anxiety and depression measured by the HADS. Higher health status measured by AVS was associated with higher self-esteem and lower anxiety.

The number of comorbidities diagnosed was positively correlated with higher anxiety and depression symptoms and also inversely correlated with the self-esteem. The trait has a negative impact in the health management. We not be able to define which comorbidities is responsible by this association, once we have a restricted sample. Future studies need to pay attention to the impact from these comorbidities in the health management. These reinforce that each construct suffer multifactioral traits interference.

The present study evaluated subjective constructs of selfesteem, anxiety and depression and of activation in patients with two types of rheumatic diseases and succeed to respond to the proposed objectives. However, there were some limitations, especially concerning the size of your sample. On the other hand, the evidences found are indications that may support future studies, along with other variables, such as objective clinical evaluation (through the use of propaedeutic and laboratory results) and the effects of clinical interventions.
It is considered that the results found are evidences for health professionals to include the evaluation of these subjective constructs in the clinical evaluation of patients with rheumatic diseases, and from there, develop plans to identify and ameliorate the symptoms of anxiety and depression, elevate self-esteem and increase the degree of self-management in these individuals' health. All of these strategies aim to improve the individual's activation with rheumatic diseases, based on their self-care, greater disposition and aptitude of the individual to self-manage their chronic condition in order to obtain better health outcomes.

\section{ACKNOWLEDGEMENTS}

The original data used in this study come from the doctoral thesis "Patient Activation Measure (PAM): Adaptation and validation of the 22 and 13 items versions in a sample of Brazilians with chronic diseases", defended by Cristiane Martins Cunha, in the Program of Post-Graduation in Fundamental Nursing, University of São Paulo, USP, Ribeirão Preto, Brazil, 2016. The authors also are grateful for the "Coordenação de Aperfeiçoamento de Pessoal de Nível Superior" (CAPES) and USP for funding and support.

\section{CONFlicts OF INTEREST Disclosure}

The authors declare that they have no competing interests.

\section{REFERENCES}

[1] OLIVEIRA P, MONTEIRO P, COUTINHO M, et al. Qualidade de vida e vivência da dor crónica nas doenças reumáticas. Acta Reumatológica Portuguesa. 2009; 34: 511-519.

[2] MELO LF, DA-SILVA SL. Análise neuropsicológica de distúrbios cognitivos em pacientes com fibromialgia, artrite reumatoide e lúpus eritematoso sistêmico. Revista Brasileira de Reumatologia. 2012; 52(2): 175-188.

[3] MONAGHAN SM, LOUISE S, FIONA D, et al. Relationship between appearance and psychological distress in rheumatic diseases. Arthritis Care \& Research. 2007; 57(2): 303-309. PMid: 17330287 https://doi.org/10.1002/art. 22553

[4] VERSTAPPEN SMM, VAN ALBADA-KUIPERS GA, BIJLSMA JWJ, et al. A good response to early DMARD treatment of patients with rheumatoid arthritis in the first year predicts remission during follow up. Annals of the Rheumatic Diseases. 2005; 64(1): 38-43. PMid:15130899 https://doi.org/10.1136/ard. 2003.01492 8

[5] SCHOELS M, WONG J, SCOTT DL, et al. Economic aspects of treatment options in rheumatoid arthritis: asystematic literature review informing the EULAR recommendationsfor the management of rheumatoid arthritis. Annals ofthe Rheumatic Diseases. 2010; 69(6): 995-1003. PMid:20447950 https://doi.org/10.1136/ard. 20 09.126714

[6] PLASQUI G. The role of physical activity in rheumatoid arthritis. Physiology \& Behavior. 2008; 94(2): 270-275. PMid:18234247 https://doi.org/10.1016/j.physbeh.2007.12.012
[7] WOOLF AD. How to assess musculoskeletal conditions. History and physical examination. Best Practice \& Research Clinical Rheumatology. 2003; 17(3): 381-402.

[8] CHEHATA JC, HASSELL AB, CLARKE SA, et al. Mortality in rheumatoid arthritis: relationship to single and composite measures of disease activity. Rheumatology. 2001; 40(4): 447-452. https://doi.org/10.1093/rheumatology/40.4.447

[9] MOTA LMHD, CRUZ BA, BRENOL CV, et al. Consenso 2012 da Sociedade Brasileira de Reumatologia para o tratamento da artrite reumatoide. Revista Brasileira de Reumatologia. 2012; 52(2): 152174. https://doi .org/10.1590/S0482-50042012000200002

[10] DE MOURA CAL SFL. Revisão da literatura sobre a eficácia da intervenção psicológica no tratamento do lúpus eritematoso sistêmico. Psicologia: Teoria e Pesquisa. 2011; 27(4): 485-90. https://doi.org/10.1590/S0102-37722011000400012

[11] NEDER PRB, FERREIRA EAP, CARNEIRO JRM. Relação entre ansiedade, depressão e adesão ao tratamento em pacientes com lúpus. Revista Paraense de Medicina. 2015; 29(2): 7.

[12] HALE ED, RADVANSKI DC, HASSETT AL. The man-in-themoon face: a qualitative study of body image, self-image and medication use in systemic lupus erythematosus. Rheumatology. 2015; 54(7): 1220-1225. PMid:25550393 https://doi.org/10.1093/ rheumatology/keu448

[13] CECATTO SB, GARCIA RI, COSTA KS, et al. Perda auditiva sensorioneural no lúpus eritematoso sistêmico: relato de três casos. Revista Brasileira de Otorrinolaringologia. 2004; 70(3): 398-403. https://doi.org/10.1590/S0034-72992004000300017 
[14] ALMEIDA EF, TEIXEIRA JMB, CARDOSO MZ. Pesquisa de auto-anticorpos em pacientes com Lúpus Eritematoso Sistêmico: revisão de literatura. Revista Ciências em Saúde. 2012; 2(3): 68-78. https://doi.org/10.21876/rcsfmit.v2i3.108

[15] CASTRO FS. Pesquisa de hemoglobinopatias e talassemias em pacientes portadores de lúpus eritematoso sistêmico. [Dissertation]. [Goiânia, GO]: Pontifícia Universidade Católica de Goiás.76p.

[16] ABOURAZZAK F, EL MANSOURI L, HUCHET D, et al. Longterm effects of therapeutic education for patients with rheumatoid arthritis. Joint Bone Spine 2009; 76(6):648-653. https : //doi . or $\mathrm{g} / 10.1016 / \mathrm{j} \cdot \mathrm{jbspin} .2009 .01 .010$

[17] NETO BL, JENNINGS F, OHASHI CB, et al. Evaluation of the efficacy of an educational program for rheumatoid arthritis patients. Clinical and Experimental Rheumatology. 2009; 27(1): 28-34. PMid:19327226

[18] PFEIFFER E. A short portable mental status questionnaire for the assessment of organic brain deficit in elderly patients. American Geriatrics Society. 1975; 23(10): 433-441. https://doi.org/10.111 1/j.1532-5415.1975.tb00927.x

[19] DINI GM, QUARESMA MR, FERREIRA LM. Adaptação Cultural e Validação da Versão Brasileira da Escala de Auto-estima de Rosenberg. Medicina HUPE-UERJ. 2004; 19(1): 41-52.

[20] BOTEGA NJ, BIO MR, ZOMIGNANI MA, et al. Transtornos do humor em enfermaria de clínica médica e validação de escala de medida (HAD) de ansiedade e depressão. Revista de Saúde Pública. 1995; 29(5): 359-363. https://doi.org/10.1590/S0034-891 01995000500004

[21] HIBBARD JH, MAHONEY ER, STOCKARD J, et al. Development and Testing of a Short Form of the Patient Activation Measure. Health Services Research. 2005; 40(6): 1918-1930. PMid:16336556 https://doi.org/10.1111/j.1475-6773.2005.00438.x

[22] CUNHACM. Patient Activation Measure (PAM): Adaptação e validação das versões de 22 e de 13 itens em uma amostra de brasileiros com doenças crônicas. [Thesis]. [São Paulo, SP]: Universidade de São Paulo; 2016. 198 p.

[23] PINTO ÉB, MASO I, VILELA RNR, et al. Validation of the EuroQol quality of life questionnaire on stroke victims. Arquivos de Neuro-psiquiatria. 2011; 69(2-B): 320-323.

[24] EUROQOL GROUP. EQ-5D: a standardised instrument for use a measure of health outcome EQ-5D translations. 2010. [cited 2017 Apr 22] Available from: http://www.euroqol.org/eq-5dpro ducts.html

[25] AJZEN J, FISHBEIN M. Understanding attitudes and predicting social behaviour. New Jersey: Prentice-Hall; 1998.

[26] SANTOANTONIO J, YAZIGI L, SATO EI. Adolescentes com Lúpus Eritematoso Sistêmico: um estudo por meio do método de Rorschach. Psicologia: Teoria e Pesquisa. 2004; 20(2): 145-151. https://doi.org/10.1590/S0102-37722004000200007

[27] CAMPOS APR, SILVA CM, CASTRO SS, et al. Depressão e qualidade de vida em indivíduos com artrite reumatoide e indivíduos com saúde estável: um estudo comparativo. Revista Fisioterapia e Pesquisa. 2013; 20(4): 401-407. https ://doi .org/10.1590/S1 809-29502013000400016

[28] ROGERS HL, BROTHERTON HT, PLAZA SLO, et al. Sintomas depressivos e de ansiedade e apoio social estão associados de modo independente à qualidade de vida específica da doença em pacientes colombianos com artrite reumatoide. Revista Brasileira de Reumatologia. 2015; 55(5): 406-413. PMid:25816759 https : //doi.org/10.1016/j.rbr.2015.01.005

[29] CERVERA R, INGELMO M. Epidemiologia. In: FONT MJ. KHAMASHTA M, VILARDELE (Orgs.), Lúpus eritematoso sistêmico. Barcelona: Menarini; 1996.
[30] BONFÁ ESDO, BORBA NETO EFB. Lúpus Eritematoso Sistêmico. In: BONFÁ ESDO, IOSHINARI NH. Reumatologia para o clínico. São Paulo: Editora Rocca; 2000. 25-33 p.

[31] COSTA AFC, BRASIL MAA, PAPI JA, et al. Depressão, Ansiedade e Atividade de Doença na Artrite Reumatóide. Revista Brasileira de Reumatologia. 2008; 48(1): 7-11.

[32] AYACHE, DCG. Depressão, ansiedade, atividade da doença e perfil de auto-anticorpos em pacientes do sexo feminino com Lupus Eritematoso Sistêmico. [thesis]. [Campo Grande (MT)]: Universidade Federal de Mato Grosso do Sul; 2013. 127 p.

[33] ROMA I, ALMEIDA ML, MANSANOA NS, et al. Qualidade de vida de pacientes adultos e idosos com artrite reumatoide. Revista Brasileira de Reumatologia. 2014; 54(4): 279-286. PMid:25627223 https://doi.org/10.1016/j.rbr.2014.03.025

[34] MENDELSON C. Managing a medically and socially complex life: women living with lupus. Qualitative Health Research. 2006; 16(7): 982-997. PMid:16894227 https://doi.org/10.1177/104973 2306290132

[35] SCHOELS M, WONG J, SCOTT DL, et al. Economic aspects of treatment options in rheumatoid arthritis: a systematic literature review informing the EULAR recommendations for the management of rheumatoid arthritis. Annals of the Rheumatic Diseases. 2010; 69(6): 995-1003. PMid:20447950 https://doi .org/10.1136/ard.20 09.126714

[36] SOKKA T. Work disability in early rheumatoid arthritis. Clinical Experimental Rheumatology. 2003; 21: S71-74. PMid:14969054

[37] CLARKE AE, UROWITZ MB, MONGA N, et al. Costs associatedwith severe and non-severe SLE in Canada. Arthritis Care Research. 2014; 67(3): 431-436. PMid:25185936 https://doi.org/10.1 $002 /$ acr. 22452

[38] CORNWELL CJ, SCHMITT MH. Perceived health status, selfesteem and body image in women with rheumatoid arthritis or systemic lupus erythematosus. Research in Nursing \& Health. 1990; 13(2): 99-107. https://doi .org/10.1002/nur. 4770130206

[39] CLEANTHOUS S, NEWMAN SP, SHIPLEY M, et al. What constitutes uncertainty in systemic lupus erythematosus and rheumatoid arthritis. Psychology \& Health. 2013; 28(2): 171-188. PMid:22775405 https://doi.org/10.1080/08870446.2012. 701628

[40] ARVIDSSON S, BERGMAN S, ARVIDSSON B, et al. Experiences of healthpromoting selfcare in people living with rheumatic diseases. Journal of Advanced Nursing. 2011; 67(6): 1264-1272. PMid:21323976 https://doi.org/10.1111/j.1365-2648.20 $10.05585 . \mathrm{x}$

[41] TAYLOR B. Promoting self-help strategies by sharing the lived experience of arthritis. Contemporary Nurse. 2001; 10(1-2): 117 125. PMid:11855014 https://doi.org/10.5172/conu.10.1-2 .117

[42] WAGNER E, AUSTIN B, VON KORFFM. Organizing care for patients with chronic illness. The Milbank Quarterly. 1996; 74): 511-44.

[43] WALKER C, SWERISSEN H, BELFRAGE J. Self-management: its place in the management of Chronic illnesses. Australian Health Review. 2003; 26(2): 34-42. https://doi.org/10.1071/AHO3 $0034 \mathrm{a}$

[44] LORIG KR, RITTER P, STEWART AL, et al. Chronic disease selfmanagement program: 2-year health status and health care utilization outcomes. Medical Care. 2001; 39(11): 1217-1223. https: //doi.org/10.1097/00005650-200111000-00008

[45] WEINER IB. Princípios da interpretação do Rorschach. São Paulo: Casa do Psicólogo; 2000.

[46] BACKMAN K, HENTINEN M. Factors associated with the selfcare of home-dwelling elderly. Scandinavian Journal of Caring Sciences. 
2001; 15(3): 195-202. https://doi.org/10.1046/j.1471-671 $2.2001 .00007 . \mathrm{x}$

[47] MATTJE GD, TURATO ER. Experiências de vida com lúpus eritematoso sistêmico como relatadas na perspectiva de pacientes ambulatoriais no Brasil: um estudo clínico-qualitativo. Revista LatinoAmericana de Enfermagem. 2006; 14(4): 475-482. PMid:16967151

[48] SATO EI. Manifestações psiquiátricas da corticoterapia. Psiquiatria na Prática Médica. 2000; 33(1): 1-3.

[49] MATSUKAWA Y, SAWADA S, HAYAMA T, et al. Suicide in pa- tients with systemic lupus erythematosus: a clinical analysis of seven suicidal patients. Lúpus. 1994; 3(1): 31-35.

[50] ARAÚJO AD. A doença como ponto de mutação: os processos de significação em mulheres portadores de lúpus eritematoso sistêmico. [dissertation]. [Natal (RN)] Universidade Federal do Rio Grande do Norte; 2004. 170 p.

[51] FIGUEIREDO J, GIGLIO J, BOTEGA N. Tratamento psicológico: psicoterapia de apoio, relaxamento, meditação. In: BOTEGA NJ (Ed.), Prática psiquiátrica no hospital geral: interconsulta e emergência. Porto Alegre: Artmed. 2006. 484-496 p. 